\title{
Precursor of shish-kebab in isotactic polystyrene under shear flow
}

\section{AUTHOR(S):}

Hayashi, Yuji; Matsuba, Go; Zhao, Yunfeng; Nishida, Koji; Kanaya, Toshiji

\section{CITATION:}

Hayashi, Yuji ... [et al]. Precursor of shish-kebab in isotactic polystyrene under shear flow. Polymer 2009, 50(9): 2095-2103

\section{ISSUE DATE:}

2009-04-24

URL:

http://hdl.handle.net/2433/123398

\section{RIGHT:}

Copyright @ 2009 Elsevier; この論文は出版社版でありません。引用の 際には出版社版をご確認ご利用ください。; This is not the published version. Please cite only the published version. 
Precursor of Shish-kebab in isotactic polystyrene under shear flow

Yuji Hayashi, Go Matsuba, Yunfeng Zhao, Koji Nishida and Toshiji Kanaya

Institute for Chemical Research, Kyoto University, Uji, Kyoto-fu 611-0011, Japan

Abstract. We performed polarized optical microscope (POM), depolarized light scattering (DPLS) and small- and wide-angle X-ray scattering measurements on the structure formation process or the crystallization process of isotactic polystyrene (iPS) under shear flow below and above the nominal melting temperature $T_{\mathrm{m}}$. It was found that an anisotropic oriented structure termed here as a string-like object was formed in $\mu \mathrm{m}$ scale even above the nominal melting temperature and stable for more than 24 hours, but melted at around $270{ }^{\circ} \mathrm{C}$ far above the nominal melting temperature. The string-like object acts as a nucleation agent for the folded chain lamella crystal (or the kebab), and was assigned to a precursor of the shish-kebab. We also examined the shear rate dependence of the structure formation to find a critical shear rate for the formation of the string-like object, suggesting the relaxation of the chains plays an important role in the formation of the structure. Based on the results we have discussed the inner structure of the string-like object.

Keywords: precursor, shish-kebab, shear flow, isotactic polystyrene 


\section{Introduction}

Extensive studies were carried out on polymer crystallization under flows because polymers crystallize under various kinds of flows during the processes and the properties are dominated by the crystal structure and the final morphology formed during the crystallization process [1-3]. It is well known that the so-called shish-kebabs are formed during crystallization under flows such as shear, elongation and mixed flows, which are made of an extended chain crystal (shish) in the central core and periodically grown folded chain lamella crystals (kebabs) on the shish in the simplest case [4-8]. Recent researches have revealed more complex structure as well as formation mechanisms of the shish-kebab [9-12]. It is believed that the shish-kebab structure is a molecular basis of ultra-high modulus and ultra-high strength fiber [4-8]. This also promoted extensive studies on polymer crystallization under various kind flows. However, the formation mechanism of the shish-kebab is not well understood regardless the considerable efforts. Recent development of advanced characterization techniques such as synchrotron radiation (SR) x-ray scattering, neutron scattering and light scattering has shed light on the substantial nature of the polymer crystallization under flow. Some of these works have focused on the structural formation in the early stage of the crystallization under flow using "short term shearing" technique[13] because it often governs or at least affects the final structure deeply. One of the most important issues in these studies is a precursor of the shish-kebab. In-situ small-angle and wide-angle x-ray scattering (SAXS and WAXS) studies on isotactic polypropylene (iPP) and polyethylene (PE) after pulse shear [14,15] have shown that a scaffold or network of oriented structures is formed prior to the full-crystallization. In-situ birefringence measurements on iPP after short term shearing by Kornfield et al. [16-18] 
suggested formation of a precursor of the shish-kebab structure. The same group [19] also have studied effects of the high molecular weight (HMW) component using model blends of HMW isotactic polypropyrene $\left(M_{\mathrm{w}}=923,000\right)$ and low molecular weight (LMW) one $\left(M_{\mathrm{w}}=186,000\right)$, both of which have rather narrow molecular weight distributions, and found that the role of the HMW component in shear-induced crystallization is cooperative, enhanced by the entanglements among the long chains. These studies as well as other ones [20-23] have demonstrated that a precursor of the shish is formed in the very early stage during the crystallization process after the shear. Furthermore, other works reported [13,23-26] that similar precursors were observed even above the nominal melting temperatures. Somami et al. have shown in SAXS measurements on iPP [14] that shear induced oriented structures or aggregates of polymer molecules were developed even above the nominal melting temperature. Alfonso et al. $[24,25]$ produced a precursor of the shish of isotactic polystyrene (iPS) in the melt at $260{ }^{\circ} \mathrm{C}$ above the nominal melting temperature by pulling a single fiber through a thin layer melt. Fiber pulling experiments were also done on poly(1-butene) melt to estimate the lifetime of the precursor [26]. Similar precursors above the nominal melting temperature were also reported for a blend of ultra-high molecular weight polyethylene (PE) and low molecular weight PE and for some polymers even near the equilibrium melting temperature [27,28].

Regardless the considerable efforts we have not had a final picture of the precursor. In some works the precursor was observed as streak-like scattering normal to the flow direction by SAXS $[9,14]$, showing that the precursor is in tens nm scale. On the other hand, in other works [16-18,22] the precursor was observed by LS and POM, suggesting that the precursor has $\mu \mathrm{m}$ scale structure. In our resent SANS 
measurements [12] we found that a very large oriented structure in $\mu \mathrm{m}$ scale including a small shish (extended chain crystal) with $\sim 10 \mathrm{~nm}$ diameter. This result implies that the oriented structure in $\mu \mathrm{m}$ scale works as a precursor of shish in $\mathrm{nm}$ scale. It is evident that the structure study in a wide length scale of $\mathrm{nm}$ to $\mu \mathrm{m}$ is absolutely important to elucidate the precursor. Another problem that was not solved is if the precursor includes crystals or not, or in which experimental condition the precursor includes crystal and in which not. As mentioned above, in the experiment by Somami et al. [14] non-crystallized shish-like structure has been observed in iPP above the nominal melting temperature by SAXS. However, a recent work by Balzano et al. [29] has shown by SAXS and WAXS measurements that PE blend of low and high molecular weight components formed needlelike precursors in tens $\mathrm{nm}$ scale with limited crystallinity even above the equilibrium melting temperature. It is a good experiment to see the invisible oriented structure (or precursor) above $T_{\mathrm{m}}$ by quenching below $\mathrm{Tm}$ to crystallize [24-26], but it gives no direct conclusions on the problem whether the precursor above $T_{\mathrm{m}}$ includes crystals or not. WAXS and SAXS measurements at high temperatures above $T_{\mathrm{m}}$ (not after quenching) are necessary to solve the problem.

In a previous paper [30], we studied structure formation process of isotactic polystyrene (iPS) after applying a pulse shear above the nominal melting temperature $T_{\mathrm{m}}$ using depolarized light scattering (DPLS) and polarized optical microscope (POM) and found that a oriented objects were formed in $\mu \mathrm{m}$ scale during an annealing process above $T_{\mathrm{m}}$, which could survive more than several hours. This was assigned to a precursor of the shish-kebab. The number of precursors was very few in the previous shear conditions, depending on the annealing temperature, and hence often no oriented objects were observed in the illuminating volume in the DPLS measurements. In 
addition, the POM measurements revealed that the oriented objects were very widely distributed in the shape and size. In such non-frequent events with the wide distributions POM observation is more appropriate than DPLS one because the former has an advantage to see individual structure while the latter sees the average one. In order to see the characteristics of the oriented objects in more details we therefore performed mainly POM measurements on the structure formation process of iPS after applying a pulse shear for various temperature and shear conditions. In addition, wideand small-angle $\mathrm{x}$-ray scattering (WAXS and SAXS) measurements were done to see the inner structure of the oriented objects above the nominal melting temperature $T_{\mathrm{m}}$.

\section{Experimental}

In this study we used isotactic polystyrene (iPS) with molecular weight $M_{\mathrm{w}}=$ 400,000 and polydispersity of $M_{\mathrm{w}} / M_{\mathrm{n}}=2.0$, where $M_{\mathrm{w}}$ and $M_{\mathrm{n}}$ are the weight-average and number-average molecular weights, respectively. The nominal melting temperature $T_{\mathrm{m}}$ determined in DSC measurements with a heating rate of $5^{\circ} \mathrm{C} / \mathrm{min}$ is $223{ }^{\circ} \mathrm{C}$.

Polarized optical microscope (POM) measurements were performed using Olympus BX50 with a video attachment. Depolarized small-angle light scattering (DPLS) measurements were carried out using a home-made apparatus with confocal collimation [31], which enables us to access a very low $q$ range down to $0.1 \mu \mathrm{m}^{-1}$ with extremely low background, where $q$ is given by $q=4 \pi \sin \theta / n \lambda, 2 \theta$ and $n$ being scattering angle and the refractive index, respectively). Light source is a He-Ne laser (80 meW) and a detector system is a complementary metal oxide semiconductor (CMOS) image sensor having a large exposure area $(20 \times 10 \mathrm{~cm})$. The range of length of scattering vector $q$ 
in this experiment is $4.5 \times 10^{-5}$ to $3.5 \times 10^{-4} \AA^{-1}$. Time-resolved small-angle x-ray scattering (SAXS) measurements were performed using an apparatus with two dimension (2D) detector installed at a beam BL15A [32] in a synchrotron radiation X-ray scattering facility, Photon Factory, KEK, in Tsukuba. The $q$ range covered by the SANS experiments was $8 \times 10^{-3}$ to $1.5 \times 10^{-1} \AA^{-1}$. Time resolved wide-angle $\mathrm{x}$-ray scattering (WAXS) measurements were done at a beam line BL40B2 in SPring-8, Nishiharima [33], covering the q range from 0.2 to $2 \AA^{-1}$.

A Linkam CSS-450 high temperature shear cell was used to control the temperature of the sample and the shear conditions. The sample was placed between two quartz plates for the POM and DPLS measurements and between two stainless steel plates with Kapton windows $50 \mu \mathrm{m}$ thick for the SAXS and WAXS measurements, respectively. The sample thickness in the cell was $300 \mu \mathrm{m}$ for the POM, DPLS, WAXS and SAXS measurements. The temperature protocol for the shear experiments is shown in Figure 1: (a) the iPS sample was heated up to $272{ }^{\circ} \mathrm{C}$ from room temperature at a rate of $30{ }^{\circ} \mathrm{C} / \mathrm{min}$, (b) held at $272{ }^{\circ} \mathrm{C}$ for $5 \mathrm{~min}$, (c) cooled down to a given annealing temperature $T_{\mathrm{a}}$ at a rate of $30{ }^{\circ} \mathrm{C} / \mathrm{min}$, (d) during the cooling process a pulse shear was applied to the sample at $250{ }^{\circ} \mathrm{C}$, (e) held at $T_{\mathrm{a}}$ for $60 \mathrm{~min}$ for the measurements during the isothermal annealing process, and then (f) again heated up to $290{ }^{\circ} \mathrm{C}$ at a rate of $5{ }^{\circ} \mathrm{C} / \mathrm{min}$ for the measurements. The iPS melt was subjected to a pulse shear at $250{ }^{\circ} \mathrm{C}$ for all the measurements except for high temperature measurements above $250{ }^{\circ} \mathrm{C}$. In the high temperature measurements above $250{ }^{\circ} \mathrm{C}$, the samples were kept at $T_{\mathrm{a}}$ for $5 \mathrm{~min}$ and subjected to a pulse shear and observed at $T_{\mathrm{a}}$. Some modified temperature protocols were also employed to see crystallization process after annealing above $T_{\mathrm{m}}$. This will be explained in the text. The range of the shear rate was from 1 to $60 \mathrm{~s}^{-1}$ and 
the shear strain was 3,000 to $48,000 \%$.

\section{Results and Discussion}

Figure 2 shows the time evolutions of the POM pictures after applying a pulse shear with the shear rate of $30 \mathrm{~s}^{-1}$ and the shear strain of $12000 \%$ at $250{ }^{\circ} \mathrm{C}$ and cooling down to various annealing temperatures $T_{\mathrm{a}}$, where $t=0$ was set to a time just after cessation of the shear. At 210 and $220{ }^{\circ} \mathrm{C}$ below the nominal melting temperature $T_{\mathrm{m}}\left(=223{ }^{\circ} \mathrm{C}\right)$ many oriented string-like objects were observed at $t=0 \mathrm{~min}$, showing that they were created during the shear. The initial string-like objects grew in length and width and some other string-like objects newly appeared during the annealing process. These are normal polymer crystallization processes under a shear flow [34]. On the other hand, at temperatures of 240,250 and $260{ }^{\circ} \mathrm{C}$ above the nominal melting temperature $T_{\mathrm{m}}(=$ $223^{\circ} \mathrm{C}$ ) a few oriented string-like objects were observed after cessation of the shear. Although the objects slightly flowed due to thermal convection, they did not disappear for $60 \mathrm{~min}$. It is clear that they are not crystals, at least folded chain crystals. These string-like objects are rather scattered in the length and the width as seen in the pictures at 240,250 , and $260{ }^{\circ} \mathrm{C}$ in Figure 2(a). Note that few very small objects were occasionally observed and disappeared with annealing time. However, normally the objects in $\mu \mathrm{m}$ sale survived more than $60 \mathrm{~min}$. We annealed the objects at $250{ }^{\circ} \mathrm{C}$ for 24 hours to see the long time behavior. In Figure 2(b), the POM pictures are shown at $0,1,19$ and $24 \mathrm{~h}$ after applying a pulse shear at $250{ }^{\circ} \mathrm{C}$. We observed that a long and wide string-like object survived for 24 hours, suggesting that the string-like objects are very stable even above the nominal melting temperature. It is noted that a small object in Figure 2(b), which is on the right side of the long one, flowed out from the view 
during the observation. As the annealing temperature exceeds $\sim 265^{\circ} \mathrm{C}$, the objects become unstable. For example, time evolution of the POM pictures of the objects formed at $270{ }^{\circ} \mathrm{C}$ is shown in Figure 2(c). An oriented string-like object was clearly observed after cessation of the shear $(t=0)$, but disappeared within $4 \mathrm{~min}$. The disappearance time depends slightly on the size of the object, but all of them disappeared at $270{ }^{\circ} \mathrm{C}$.

POM pictures of the string-like objects during the heating process from each annealing temperature to $290{ }^{\circ} \mathrm{C}$ are shown in Figure 3. The samples annealed below the nominal melting temperature grew in length and width as seen in Figure 2(a), and the grown parts around the string-like objects melted at around the nominal melting temperature $T_{\mathrm{m}}\left(=223{ }^{\circ} \mathrm{C}\right)$. However, the string-like objects created during the shearing process at $250{ }^{\circ} \mathrm{C}$ survived even above the nominal melting temperature, and melted (or disappeared) at a temperature between 265 and $270{ }^{\circ} \mathrm{C}$. The string-like object annealed above the nominal melting temperature did show small changes: the object annealed at $250{ }^{\circ} \mathrm{C}$ began to melt from the outside, and melted completely at $265{ }^{\circ} \mathrm{C}$; the object annealed at $260{ }^{\circ} \mathrm{C}$ did not show any changes up to $268{ }^{\circ} \mathrm{C}$ and finally melted at $270{ }^{\circ} \mathrm{C}$. It is clear that the string-like objects melt at a temperature between 265 and $270{ }^{\circ} \mathrm{C}$ although the disappearance temperature slightly depends on the size of the objects. To see the disappearance temperature of the string-like objects quantitatively the integrated intensity of the string-like object in the POM picture was plotted as a function of temperature during the heating process at a rate of $5^{\circ} \mathrm{C} / \mathrm{min}$ in Figure 4, which shows an average melting behavior. A decrease in the total intensity was observed at around the nominal melting temperature $T_{\mathrm{m}}\left(=223^{\circ} \mathrm{C}\right)$ for the samples annealed below the nominal melting temperature. This is due to the melting of the 
grown parts during the annealing, which must be folded chain lamella crystals. However, there remains the intensity even above $T_{\mathrm{m}}$, which corresponds to the string-like objects seen in Figure 3 and completely disappeared between 265 and $270{ }^{\circ} \mathrm{C}$. The samples annealed above $T_{\mathrm{m}}$ also have some intensities from the string-like objects, depending on the annealing temperature, and they decreased with increasing the temperature, and then finally came to zero at around $270{ }^{\circ} \mathrm{C}$. Note that the disappearance temperature slightly depends on the initial annealing temperature.

The above experiments suggest that the string-like object created above the nominal melting temperature acts as a nucleating agent when it is annealed below the nominal melting temperature. In order to see this clearly we performed the following experiment. First we created the string-like object at $250^{\circ} \mathrm{C}$, and then cooled down to $210{ }^{\circ} \mathrm{C}$ to observe the crystallization process. After $60 \mathrm{~min}$ annealing at $210{ }^{\circ} \mathrm{C}$ for crystallization, the sample was heated up to $290{ }^{\circ} \mathrm{C}$ at a heating rate of $5{ }^{\circ} \mathrm{C} / \mathrm{min}$. POM pictures at $250{ }^{\circ} \mathrm{C}$, during the annealing process at $210^{\circ} \mathrm{C}$ and the heating process to $290{ }^{\circ} \mathrm{C}$ are shown in upper row in Figure 5. Just after applying shear flow at $250{ }^{\circ} \mathrm{C}$ we observed long string-like objects in the view in Figure 5(a). Cooing to the $210{ }^{\circ} \mathrm{C}$, the crystal growth was clearly observed on the string-like objects (Figures 5(b) and (c)). During the heating process, the grown crystals on the string-like objects melted at around the nominal melting temperature $\left(=223{ }^{\circ} \mathrm{C}\right.$ ) (Figure $5(\mathrm{~d})$ and $\left.(\mathrm{e})\right)$ and the string-like objects survived up to about $265^{\circ} \mathrm{C}$ (Figure 5(f)). This result clearly shows that the string-like object acts as a nucleating agent to produce oriented folded chain lamella crystals, suggesting that the string-like object is a precursor of the shish-kebab. In order to see the inner structure of the crystals created on the string-like object during the annealing at $210{ }^{\circ} \mathrm{C}$ we performed SAXS measurements on the iPS under the same 
temperature and shear conditions as the POM experiments. The two dimensional (2D) SAXS patterns observed at $250{ }^{\circ} \mathrm{C}$, at $210{ }^{\circ} \mathrm{C}$ during the annealing process and at $240{ }^{\circ} \mathrm{C}$ during the heating process are shown in lower row in Figures 5(a)-(f), respectively. We observed two-spots pattern along the flow direction, corresponding to the long period between the lamellae (or kebabs), which was detected at around $10 \mathrm{~min}$ after quenching to $210^{\circ} \mathrm{C}$ and grew with the annealing time (Figures 5(b)-(c)). In the heating process the two-spots pattern disappeared at around the nominal melting temperature $\left(=223{ }^{\circ} \mathrm{C}\right)$ (Figure $\left.5(\mathrm{~d})-(\mathrm{e})\right)$. The result again suggests that the string-like object acts as a nucleating agent for the kebab, which may grow epitaxially on the string-like objects. The string-like object could be assigned to a precursor of the shish-kebab. Note that we did not observe the scattering corresponding to the string-like structure in SAXS. The string-like object is too large to observe by SAXS.

In the next we have examined the effects of the shear rate and shear strain on the formation of the string-like objects. Figure 6 shows the POM pictures of the string-like objects just after applying a pulse shear for various shear rates and temperatures. The shear stain was $12000 \%$ for all the measurements. It is clear that the number of the string-like objects increases with the shear rate. In order to analyze the data quantitatively we need a measure for the string-like object formation. We employed the number of the string-like objects just after applying pulse shear as the measure. As seen in Figures 2, 3 and 7 there are wide variety of the string-like object in length, width and shape, and sometimes it is branched and separated into two when it is heated up (see structure \#3 in Figure 7). Hence, it is not easy to count the number. For simplicity, however, we counted the number of the string-like objects regardless the shape, length and width. If it is branched we counted it as one if both of the branches 
melt simultaneously when they are heated up to $270{ }^{\circ} \mathrm{C}$ (see Figure 7). Thus counted number of the string-like objects was plotted in Figure 8 as a function of the shear rate for the annealing temperatures of $230,240,250$ and $260{ }^{\circ} \mathrm{C}$ above the nominal melting temperature $T_{\mathrm{m}}$. The data points are very much scattered. The error bars were estimated in several measurements. One of the reasons for the large deviation is small number of the objects under the present shear and temperature conditions. In any case the number of the string-like objects above the nominal melting temperature decreases with the shear rate at each annealing temperature. There seems a critical shear rate for the string-like object formation as observed in the crystallization process of polyethylene [34] and isotactic polypropylene [32]. Drawing a straight line by eye we have evaluated the critical shear rate to be $1 \mathrm{~s}^{-1}$ for each temperature for the shear strain of $12,000 \%$. It is suggested that the relaxation of polymer chains plays an important role for the string-like object formation. Unfortunately it is hard to say if there is a temperature dependence on the critical shear rate due to the large error although we believe there exists.

We also evaluated the number of the string-like objects as a function of the shear strain for the shear rate of $30 \mathrm{~s}^{-1}$ at $250{ }^{\circ} \mathrm{C}$. The result is shown in Figure 9. It is clear that the number of the objects increases with the shear strain although the error bars are very large. If there is a critical shear strain for the shear rate of $30 \mathrm{~s}^{-1}$ at $250{ }^{\circ} \mathrm{C}$, it is very low, at most below $3000 \%$. This result suggests that if the shear rate is above the critical value the string-like objects are formed even though the shear strain is very low, implying that the shear rate is a leading factor for the string-like object formation.

Seeing Figure 8 closely, one can find a very interesting phenomenon. The number 
of the string-like objects is not zero even below the critical shear rate $\left(\sim 4 \mathrm{~s}^{-1}\right)$. In order to see what happen in the low shear rate region below $4 \mathrm{~s}^{-1}$ we have conducted the following experiment. After a pulse shear with the shear rate of $1 \mathrm{~s}^{-1}$ and shear strain of $12,000 \%$ at $250{ }^{\circ} \mathrm{C}$ the sample was annealed for $30 \mathrm{~min}$, and then cooled down to $210{ }^{\circ} \mathrm{C}$ for $30 \mathrm{~min}$ crystallizing. Finally it was heated up to $290{ }^{\circ} \mathrm{C}$ at a rate of $5{ }^{\circ} \mathrm{C} / \mathrm{min}$. Both of the POM and DPLS measurements were performed to see the structure change during the above-mentioned annealing processes and heating process. The results of the POM and DPLS measurements are shown in Figure 10. Just after applying the pulse shear $(t=0)$ the streak-like scattering in the DPLS corresponding to the string-like object was clearly observed, but it disappeared within several minutes. In the POM image, however, nothing is observed even at $t=0$. This is not a contradictory result. Once in several measurements we observed no string-like objects in the DPLS and/or POM view, showing that very few formation of the string-like objects. Even when the string-like object was created in the present temperature and shear condition $\left(1 \mathrm{~s}^{-1}\right.$ at $\left.250{ }^{\circ} \mathrm{C}\right)$ it is very small and unstable compared with that created at the shear rate above $4 \mathrm{~s}^{-1}$. After annealing at $250{ }^{\circ} \mathrm{C}$ for $30 \mathrm{~min}$, the sample was cooled down to $210^{\circ} \mathrm{C}$ and annealed. The POM and DPLS results are shown in Figure 10 (b) during the annealing process at $210^{\circ} \mathrm{C}$. At the beginning we did not observe any changes in the POM and DPLS pictures, but we observed gradual formation of some oriented structure along the flow direction in the POM picture and the corresponding streak-like scattering in the DPLS pictures as seen in Figure 10(b). It strongly suggests that there remains an oriented structure even after the disappearance of the string-like object in the DPLS and POM pictures, and it may act as an oriented nucleating agent for the following crystallization. As seen in Figure 10(b) the oriented 
object formed during the annealing at $210{ }^{\circ} \mathrm{C}$ is not large compared with the string-like objects created at the shear rate above $4 \mathrm{~s}^{-1}$ and the degree of orientation is not high, implying that the invisible oriented structure may have rather small and disordered structure. Following the annealing at $210^{\circ} \mathrm{C}$ the sample was heated up to $290{ }^{\circ} \mathrm{C}$ at a heating rate of $5{ }^{\circ} \mathrm{C} / \mathrm{min}$. The DPLS and POM pictures during the heating process are shown in Figure 10(c). It is very clear that the oriented objects created during the annealing process at $210{ }^{\circ} \mathrm{C}$ melt at around the nominal melting temperature $T_{\mathrm{m}}(=$ $223^{\circ} \mathrm{C}$ ), meaning that the visible objects consist of folded chain lamella crystals. It is considered that the string-like object is occasionally formed in a low shear region below $4 \mathrm{~s}^{-1}$ and could survive for more than $30 \mathrm{~min}$ at $250{ }^{\circ} \mathrm{C}$ and could act as an oriented nucleating agent for the folded chain lamella crystals although it is invisible at $250{ }^{\circ} \mathrm{C}$. This must be due to the low degree of orientation and/or very small size of the string-like object formed below the critical shear rate.

We would like to consider the inner structure of the string-like object based on the present observations. In order to confirm if the string-like object includes crystals we performed wide-angle x-ray scattering (WAXS) measurements on the string-like object of iPS during annealing process at $250{ }^{\circ} \mathrm{C}$ after applying a pulse shear with shear rate of $30 \mathrm{~s}^{-1}$ and strain of $12,000 \%$. The observed 1D WAXS patters are shown in Figure 11 for the directions parallel and normal to the flow direction. We did not observe any signs of crystallization in the WAXS patterns in both the directions. This suggests that the string-like object has no crystallinity or very limited crystallinity below the detection limit of the present WAXS measurement. As shown above, the string-like object melts at around $270{ }^{\circ} \mathrm{C}$. In the beginning of the study we considered that this temperature was related to the equilibrium melting temperature $T_{\mathrm{m}}{ }^{0}$ : the thermodynamic 
quantity which is defined as the melting temperature of equilibrium crystal of infinite size. There are several reports on the equilibrium melting temperature $T_{\mathrm{m}}{ }^{0}$ of iPS [36-38], but they are rather scatted. The value of $T_{\mathrm{m}}{ }^{0}$ evaluated on the basis of the Hoffman-Weeks method [39] is $242{ }^{\circ} \mathrm{C}$ [36,37] while the recent value evaluated by the Gibbs-Thomson method [40] is $289^{\circ} \mathrm{C}$ [38]. In the paper by Strobl et al. [38] the difference between the reported values was carefully discussed and the value $289{ }^{\circ} \mathrm{C}$ is more reliable at the moment. If the string-like object has very limited crystallinity the crystals must be rather large because the melting temperature is above the nominal melting temperature $\left(=223{ }^{\circ} \mathrm{C}\right)$, but not extended chain crystals because the melting temperature is below the equilibrium melting temperature $\left(=289^{\circ} \mathrm{C}\right)$. According to Strobl et al. the length of the crystal is about $20 \mathrm{~nm}$ (see Figure 3(b) in Reference [38]). If the string-like object does not include any crystals, we have to consider some other mechanism for the stabilization. One possibility is that the string-like object has liquid crystal-like structure because iPS chains can easily form $3 / 1$ helix structure which is rather rigid and could work as mesogen in liquid crystals [41, 42]. However, we have no final conclusions on the inner structure of the string-like structure.

\section{Conclusion}

We have studied structure formation process of iPS after applying a pulse shear blew and above the nominal melting temperature $T_{\mathrm{m}}\left(=223{ }^{\circ} \mathrm{C}\right)$. It was found that the oriented objects, which termed string-like object in this paper, were formed even above the melting temperature $T_{\mathrm{m}}$ in $\mu \mathrm{m}$ scale and survived more than $24 \mathrm{~h}$, but melted at around $270{ }^{\circ} \mathrm{C}$. This string-like object acts as a nucleating agent for lamella crystals 
(or kebabs), and hence assigned to the precursor of the shish-kebab. It is clear that the string-like object in $\mu \mathrm{m}$ scale is neither the shish nor the extended chain crystals. The WAXS measurements on the string-like object did not show any sign of the crystals, suggesting that the string-like object has no crystallinity or very limited crystallinity below the detection limit. If the string-like object has very limited crystallinity the crystals must be rather large in size, being about $20 \mathrm{~nm}$, but not extended chain crystals because the melting temperature is below the equilibrium melting temperature (= $289{ }^{\circ} \mathrm{C}$ ). If the string-like object does not include any crystals, the string-like object has possibly liquid crystal-like structure where rigid 3/1 helix of iPS chains could work as mesogens.

\section{Refferences}

1. Ward IM. Structure and Properties of Oriented Polymers. New York: Wiley, 1975.

2. Ziabicki A. Fundamentals of Fiber Formation. New York: Wiley, 1976.

3. Walczak ZK. Processses of Fiber Formation. Amsterdam: Elsevier, 2002.

4. Odell JA, Grubb DT, and Keller A. Polymer 1978;19:617-626.

5. Bashir Z, Odell JA, and Keller A. J. Mater. Sci. 1984;19:3713-3725.

6. Keller A and Odell JA. Colloid Polym. Sci. 1985;263:181-201.

7. Bashir Z, Hill MJ, and Keller A. J. Mater. Sci. Lett. 1986;5:876-878.

8. Keller A and Kolnaar JWH. Flow-Induced Orientaion and Structure Formation. In: Meijer HEH, editor. Processing of Polymers, vol. 18. New York: VCH, 1997. pp. 189-268.

9. Hsiao SB. Role of Chain Entanglement Newtwork on Formation of 
Flow-Induced Crsytallization Precursor Structure. In: Reiter G and Strobl G, editors. Progress of Understanding of Polymer Crystallization, Lecture Notes in Physics, vol. 714. Berline: Springer, 2007. pp. 133-149.

10. Hsiao B, Yang L, Somani RH, Avila-Orta CA, and Zhu L. Phys. Rev. Lett. 2005;94:117802-117801-118902-117804.

11. Kimata S, Sakurai T, Nozue Y, Kasahara T, Yamaguchi N, Karino T, Shibayama M, and Kornfield JA. Science 2007;316:1014-1017.

12. Kanaya T, Matsuba G, Ogino Y, Nishida K, Shimizu HM, Shinohara T, Oku T, Suzuki J, and Otomo T. Macromolecules 2007;40:3650-3654.

13. Jerschow P and Janeschitz-Kriegel H. Int. Polym. Process 1997;12:72-77.

14. Somani RH, Yang L, and Hsiao BS. Physica A 2002;304:145-157.

15. Yang L, Somani RH, Sics I, Hsiao BH, Kolb R, Fruitwala H, and Ong C. Macromolecules 2004;37:4845-4859.

16. Kumaraswamy G, Issaian AM, and Kornfield JA. Macromolecules $1999 ; 32: 7537-7547$.

17. Kumaraswamy G, Verma RK, Issaian AM, Wang P, Kornfield JA, Yeh F, Hsiao B, and Olley RH. Polymer 2000;41:8934-8940.

18. Kumaraswamy G, Kornfield JA, Yeh F, and Hsiao B. Macromolecules 2002;35:1762-1769.

19. Seki M, Thurman DW, Oberhauser JP, and Kornfield J. Macromolecules 2002;35:2583-2594.

20. Nogami K, Murakami S, Katayama K, and Kobayashi K. Bull. Inst. Chem. Res., Kyoto Univ. 1977;55:227-236.

21. Pogodina NV, Siddiquee SK, Egmond JWv, and Winter HH. Macromolecules 
$1999 ; 32: 1167-1174$.

22. Pogodina NV, Lavrenko VP, Srinivas S, and Winter HH. Polymer $2001 ; 42: 9031-9043$

23. Elmoumni A, Winter HH, Waddon AJ, and Fruitwala H. Macromolecules 2003;36:6453-6461.

24. Gutierrez MG, Aalfonso GC, Riekel C, and Azzurri F. Macromolecules $2004 ; 37: 478-485$.

25. Azzurri F and Alfonso GC. Macromolecules 2008;41:1377-1383.

26. Azzurri F and Alfonso GC. Macromolecules 2005;38:1723-1728.

27. Kahk JK, Zuo F, and Hsiao BS. J. Appl. Cyst. 2007;40:s48-s51.

28. Janeschitz H and Edar G. J. Macromol. Sci., Part B: Physics 2007;46:591-601.

29. Balzano L, Kukalyekar N, Rastogi S, Peters GWM, and Chadwick JC. Phys. Rev. Lett. 2008; 100: 048302-1-048302-4

30. Kanaya T, Takayama Y, Ogino Y, Matsuba G, and Nishida K. Precursor of primary nucleation in isotactic polystyrene induced by shear flow. In: Reiter G and Strobl G, editors. Progress of Understanding of Polymer Crystallization, Lecture Notes in Physics, vol. 714. Berline: Springer, 2007. pp. 91-99.

31. Nishida K, Ogawa H, Matsuba G, Konishi T, and Kanaya T. J. Appl. Cryst. 2008;42:in press.

32. Amemiya Y, Wakabayashi K, Hamanaka T, Wakabayashi T, and Hashizume. H. Nucl. Instr. and Meth. 1983;208:471-477.

33. Shimizu N and Inoue K. SPring-8 Beamkine Handbook 2003:90.

34. Fukushima H, Ogino Y, Matsuba G, Nishida K, and Kanaya T. Polymer $2005 ; 46: 1878-1885$. 
35. Ogino Y, Fukushima H, Takahashi N, Matsuba G, Nishida K, and Kanaya T. Macromolecules 2006;39:7617-7642.

36. Boon J, Challa G, and Krevelen DWV. J. Polym. Sci. A-2 1968;6:1800-.

37. Lemstra PJ, Kooistra T, and Chara GJ. J. Polym. Sci., Part A-2 1972;10:823-833.

38. Al-Hussein M and Strobl G. Macromolecules 2002;35:1672-1676.

39. Hoffman JD and Weeks JJ. J. Natl. Bur. Stand. (U.S.) 1962;A66:13.

40. Wunderlich B. Macromolecular Physics. Berlin: Springer, 1980.

41. Kaji K, Nishida K, Kanaya T, Matsuba G, Konishi T, and Imai M. Adv. Polym. Sci. 2005; 191:187-240.

42. Matsuba G, Nishida K, Kanaya T, Kaji K, and Imai M. Polym. J. $1999 ; 32: 722-727$. 
Figure captions

Figure 1. Temperature protocol for the shear experiments on isotactic polystyrene (iPS).

Figure 2. Time evolution of POM pictures of iPS during the annealing process at various temperatures after applying a pulse shear with shear rate $30 \mathrm{~s}^{-1}$ and shear strain $12,000 \%$. (a): up to $60 \mathrm{~min},(\mathrm{~b})$; at $250{ }^{\circ} \mathrm{C}$ up to $24 \mathrm{~h}$, (c): at $270{ }^{\circ} \mathrm{C}$ up to $4 \mathrm{~min}$. Note that the nominal melting temperature of iPS is $223^{\circ} \mathrm{C}$.

Figure 3. POM pictures of iPS during the heating process after applying a pulse shear followed by annealing at various temperatures for $60 \mathrm{~min}$ (see Figure 2). Heating rate is $5{ }^{\circ} \mathrm{C} / \mathrm{min}$.

Figure 4. Temperature dependence of integrated POM intensity of iPS during the heating process from various annealing temperatures to $290{ }^{\circ} \mathrm{C}$. Heating rate is $5{ }^{\circ} \mathrm{C} / \mathrm{min}$.

Figure 5. POM (upper row) and 2D SAXS (lower row) pictures of iPS after applying a pulse shear and annealing at $250{ }^{\circ} \mathrm{C}$ for $10 \mathrm{~min}$ (a), and cooling down to $210{ }^{\circ} \mathrm{C}$ and annealing for $30 \mathrm{~min}(\mathrm{~b})$ and for $60 \mathrm{~min}$ (c). Then, the iPS was heated up to $290{ }^{\circ} \mathrm{C}$ at a heating rate of $5{ }^{\circ} \mathrm{C} / \mathrm{min}$. POM and SAXS pictures at 220 (d), 230 (e) and $260{ }^{\circ} \mathrm{C}$ (f) during the heating process.

Figure 6. POM pictures of iPS just after applying a pulse shear with various shear rates at various temperatures. The shear stain was $12000 \%$ for all the shear rates.

Figure 7. An example for counting the number of string-like objects. (a) at $250{ }^{\circ} \mathrm{C}$, (b) 
at $260^{\circ} \mathrm{C}$.

Figure 8 . Number density of the string-like objects as a function of shear rate at various annealing temperatures above the nominal melting temperature $T_{\mathrm{m}}\left(=223{ }^{\circ} \mathrm{C}\right)$. The shear stain was $12,000 \%$ for all the shear rates.

Figure 9. Number density of the string-like objects as a function of shear strain at $250{ }^{\circ} \mathrm{C}$. The shear rate was $30 \mathrm{~s}^{-1}$ for all the measurements.

Figure 10. DPLS and POM pictures after applying a pulse shear with shear rate of $1 \mathrm{~s}^{-1}$ and shear strain of $12,000 \%$ at $250{ }^{\circ} \mathrm{C}$. (a): the annealing process at $250{ }^{\circ} \mathrm{C}$, (b) the annealing process at $210^{\circ} \mathrm{C}$ after cooling, (c): the heating process from 210 to $290{ }^{\circ} \mathrm{C}$.

Figure 11. 1D WAXS profiles in the directions parallel and normal to the flow direction after applying a pulse shear with shear rate of $30 \mathrm{~s}^{-1}$ and strain of $12,000 \%$ at $250{ }^{\circ} \mathrm{C}$. 


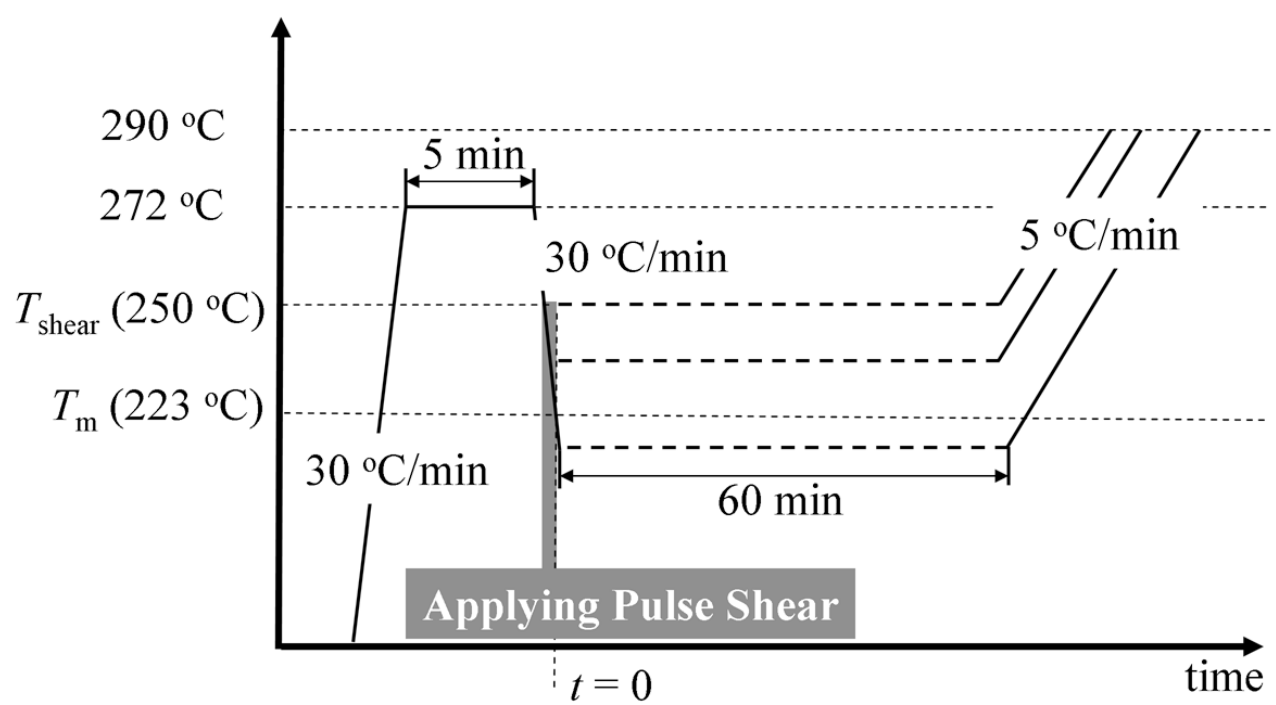

Figure 1. Temperature protocol for the shear experiments on isotactic polystyrene (iPS). 

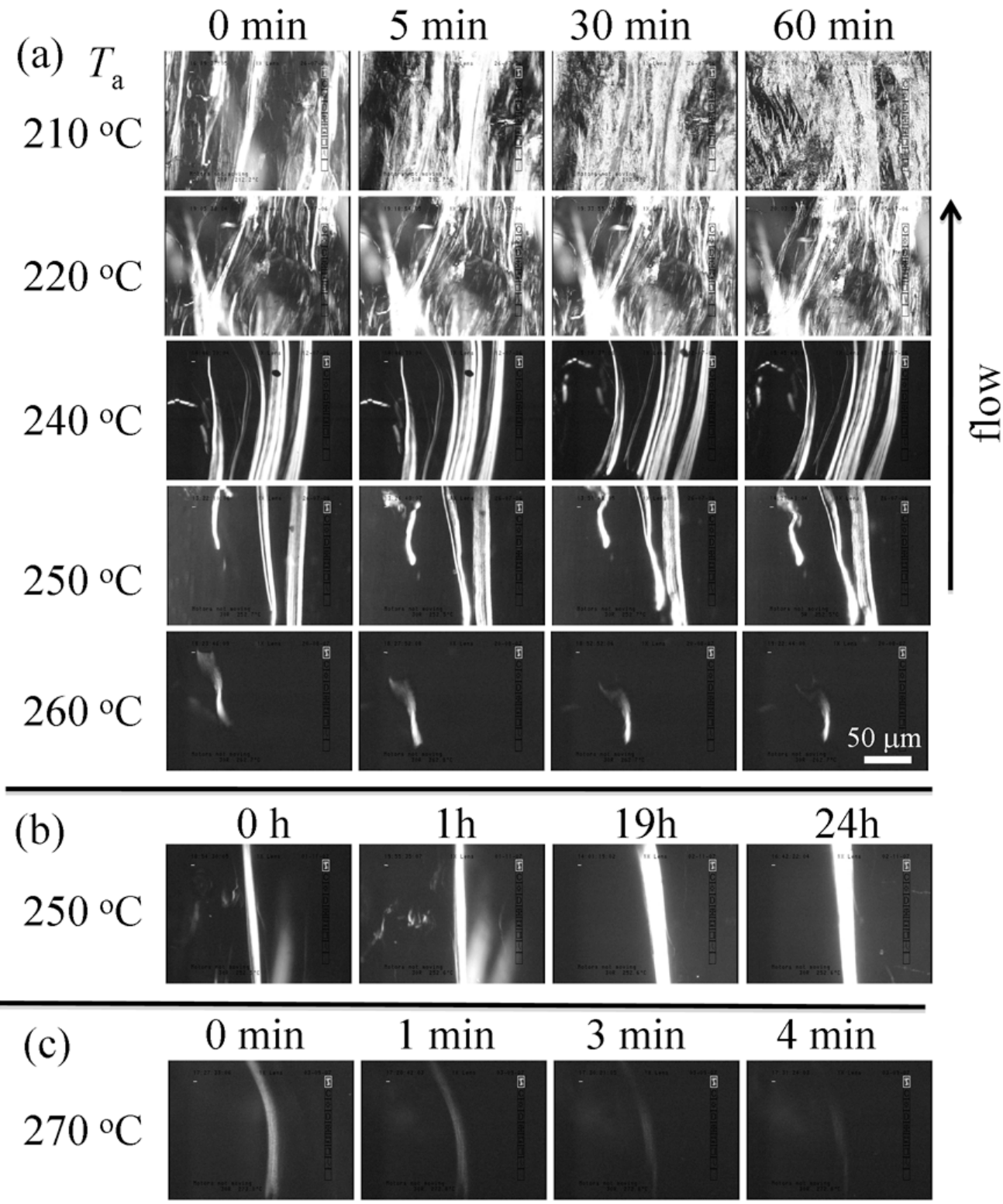

Figure 2. Time evolution of POM pictures of iPS during the annealing process at various temperatures after applying a pulse shear with shear rate $30 \mathrm{~s}^{-1}$ and shear strain $12,000 \%$. (a): up to $60 \mathrm{~min},(\mathrm{~b})$; at $250{ }^{\circ} \mathrm{C}$ up to $24 \mathrm{~h}$, (c): at $270{ }^{\circ} \mathrm{C}$ up to $4 \mathrm{~min}$. Note that the nominal melting temperature of iPS is $223{ }^{\circ} \mathrm{C}$. 


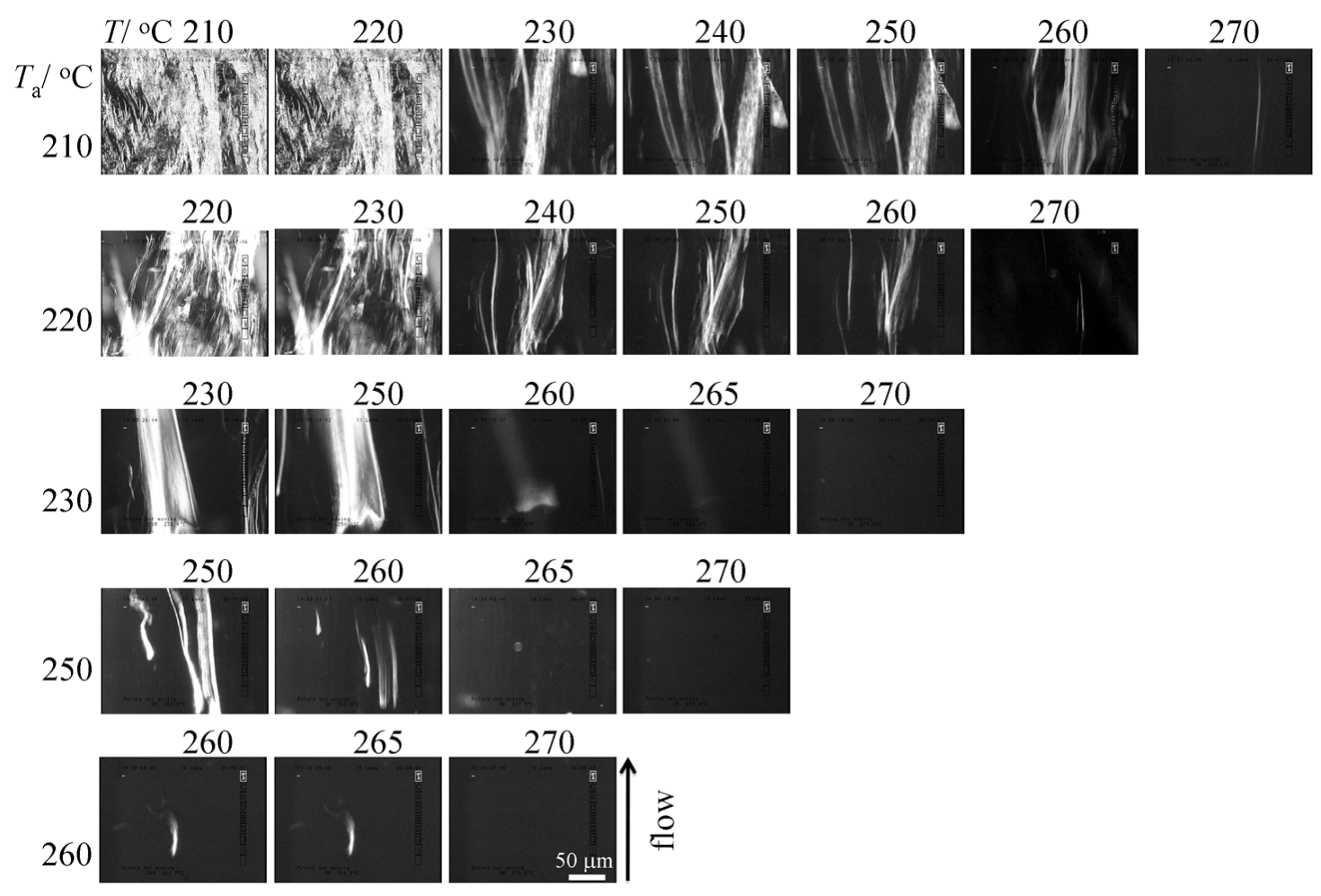

Figure 3. POM pictures of iPS during the heating process after applying a pulse shear followed by annealing at various temperatures for $60 \mathrm{~min}$ (see Figure 2). Heating rate is $5{ }^{\circ} \mathrm{C} / \mathrm{min}$. 


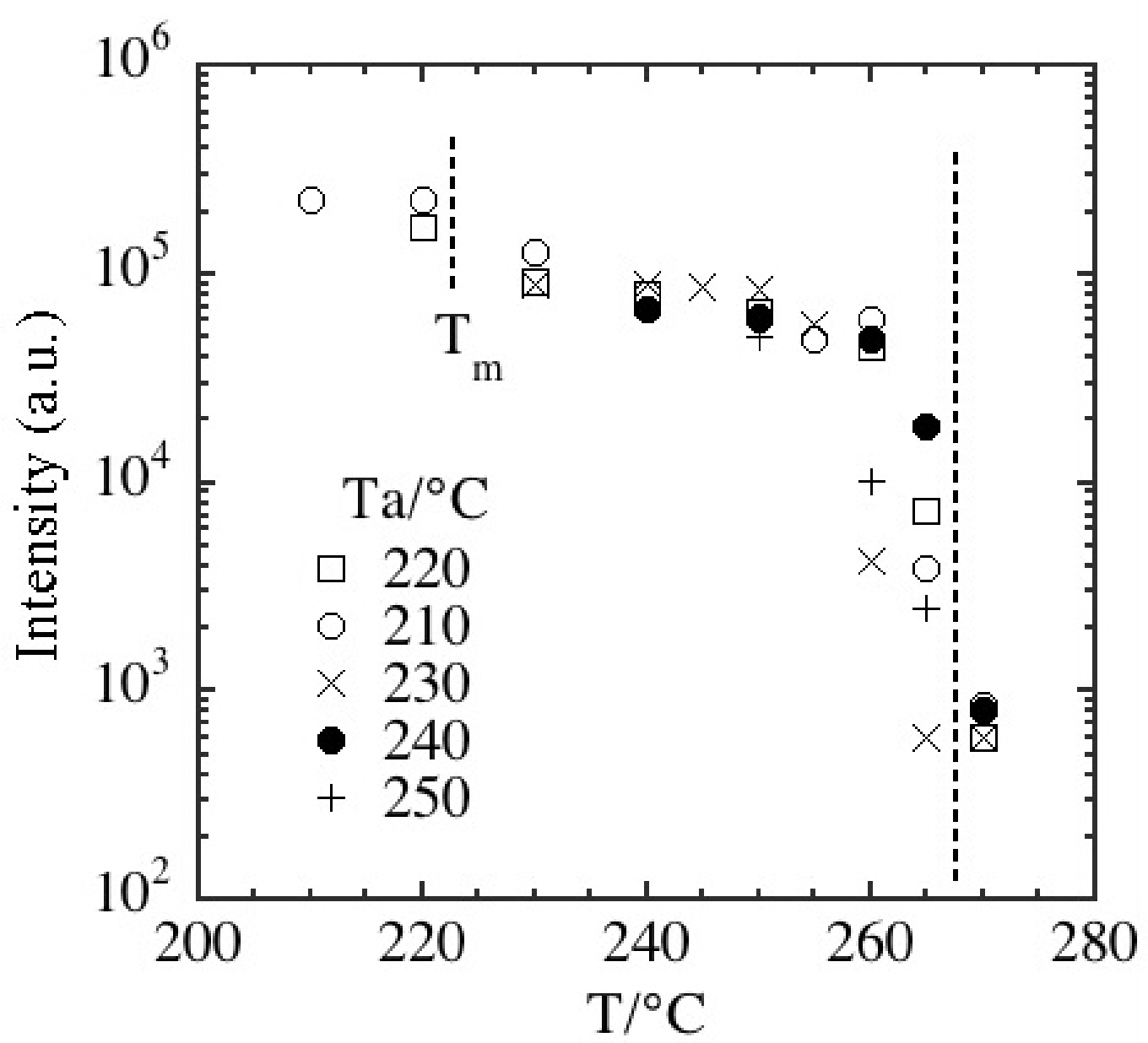

Figure 4. Temperature dependence of integrated POM intensity of iPS during the heating process from various annealing temperatures to $290{ }^{\circ} \mathrm{C}$. Heating rate is $5{ }^{\circ} \mathrm{C} / \mathrm{min}$. 


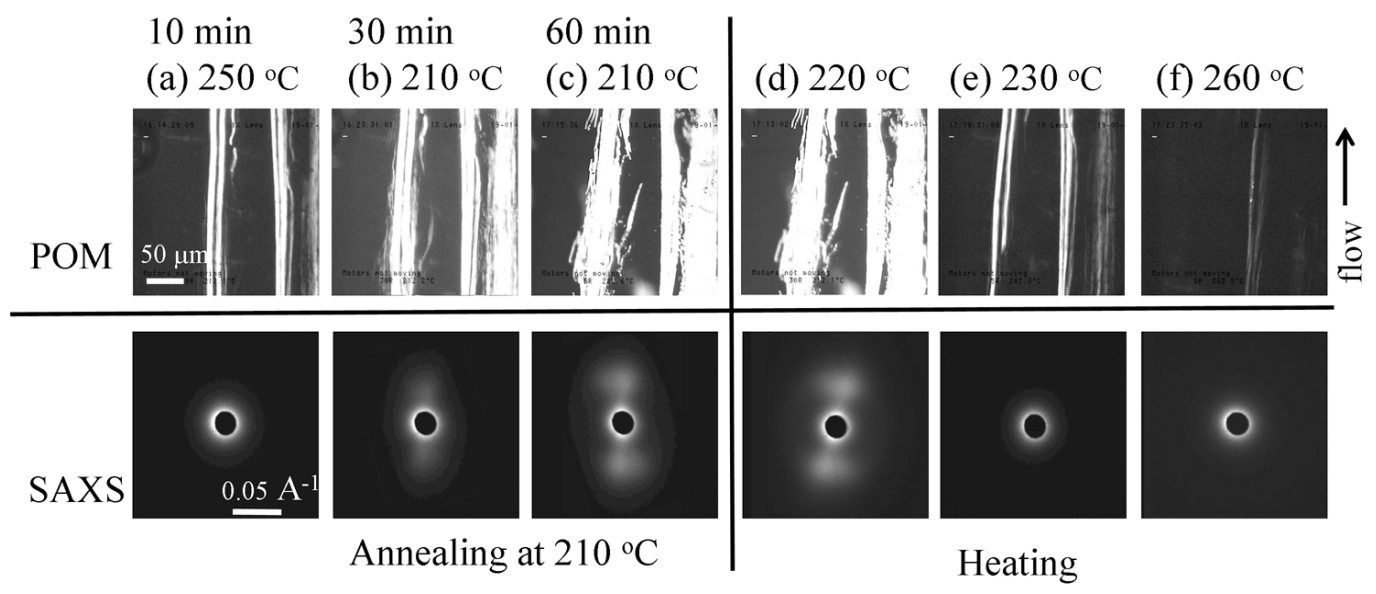

Figure 5. POM (upper row) and 2D SAXS (lower row) pictures of iPS after applying a pulse shear and annealing at $250^{\circ} \mathrm{C}$ for $10 \mathrm{~min}$ (a), and cooling down to $210^{\circ} \mathrm{C}$ and annealing for $30 \mathrm{~min}(\mathrm{~b})$ and for $60 \mathrm{~min}$ (c). Then, the iPS was heated up to $290{ }^{\circ} \mathrm{C}$ at a heating rate of $5{ }^{\circ} \mathrm{C} / \mathrm{min}$. POM and SAXS pictures at 220 (d), 230 (e) and $260{ }^{\circ} \mathrm{C}$ (f) during the heating process. 

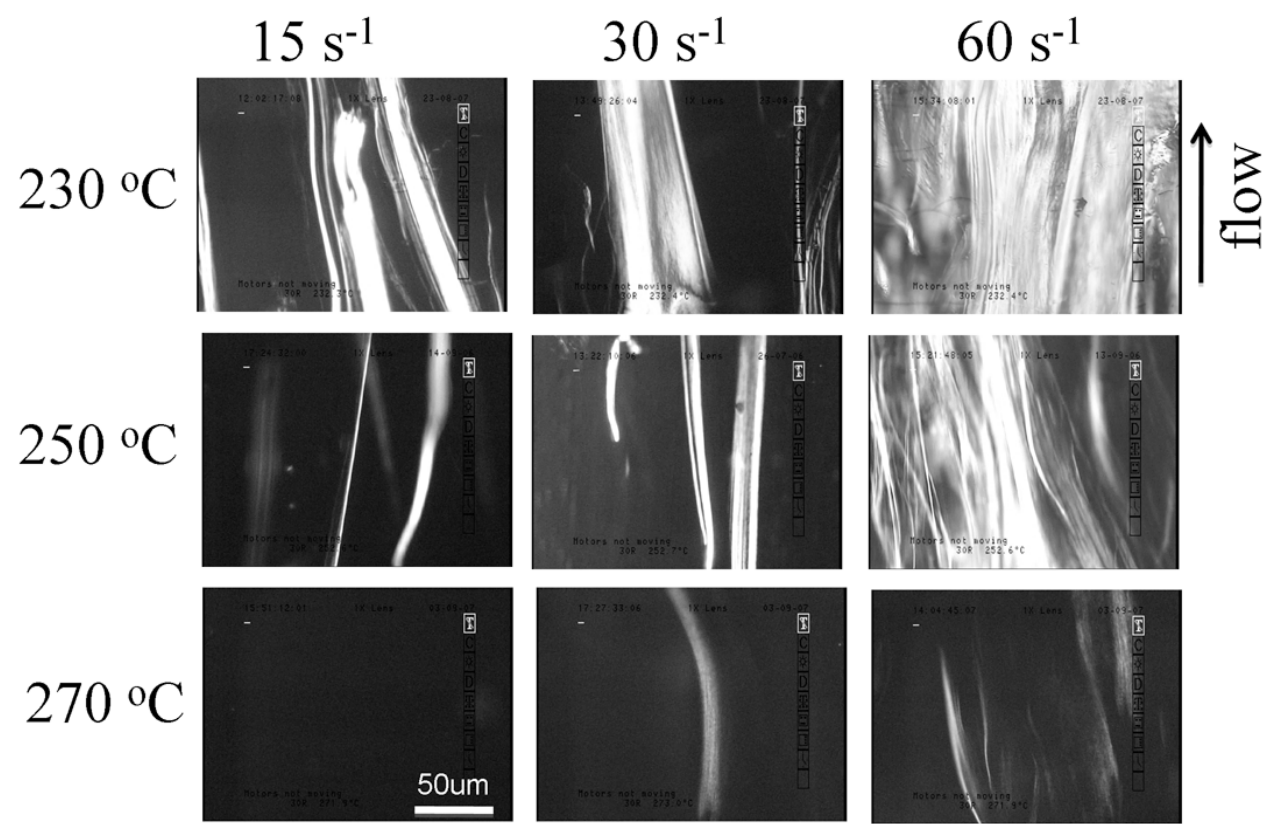

Figure 6. POM pictures of iPS just after applying a pulse shear with various shear rates at various temperatures. The shear stain was $12,000 \%$ for all the shear rates. 

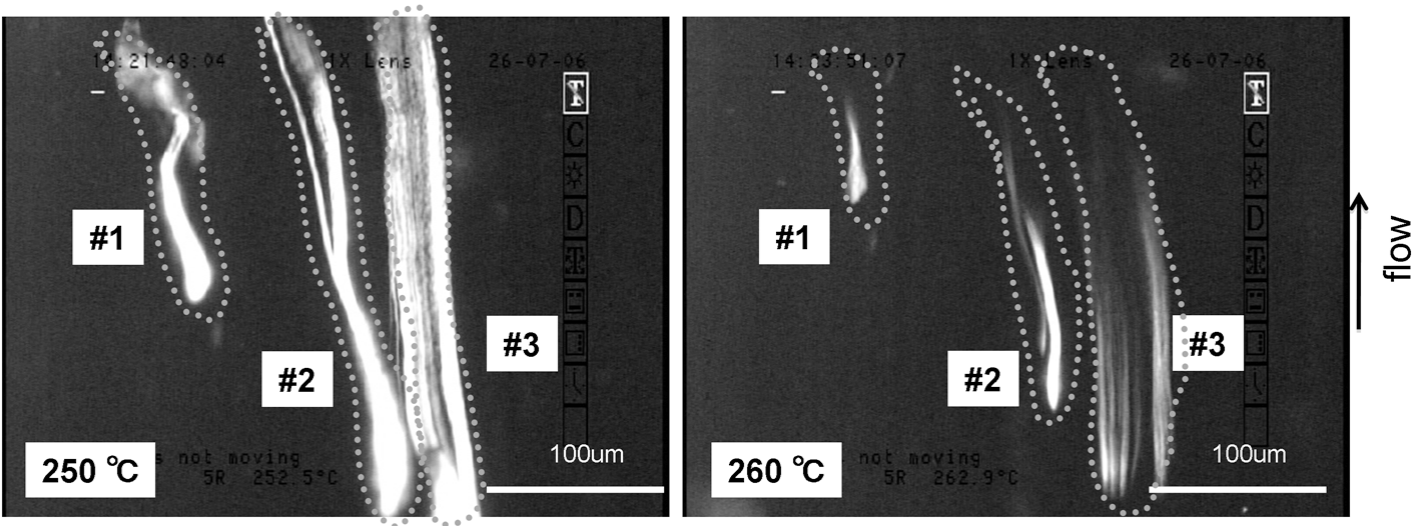

Figure 7. An example for counting the number of string-like objects. (a) at $250{ }^{\circ} \mathrm{C}$,

(b) at $260{ }^{\circ} \mathrm{C}$. 


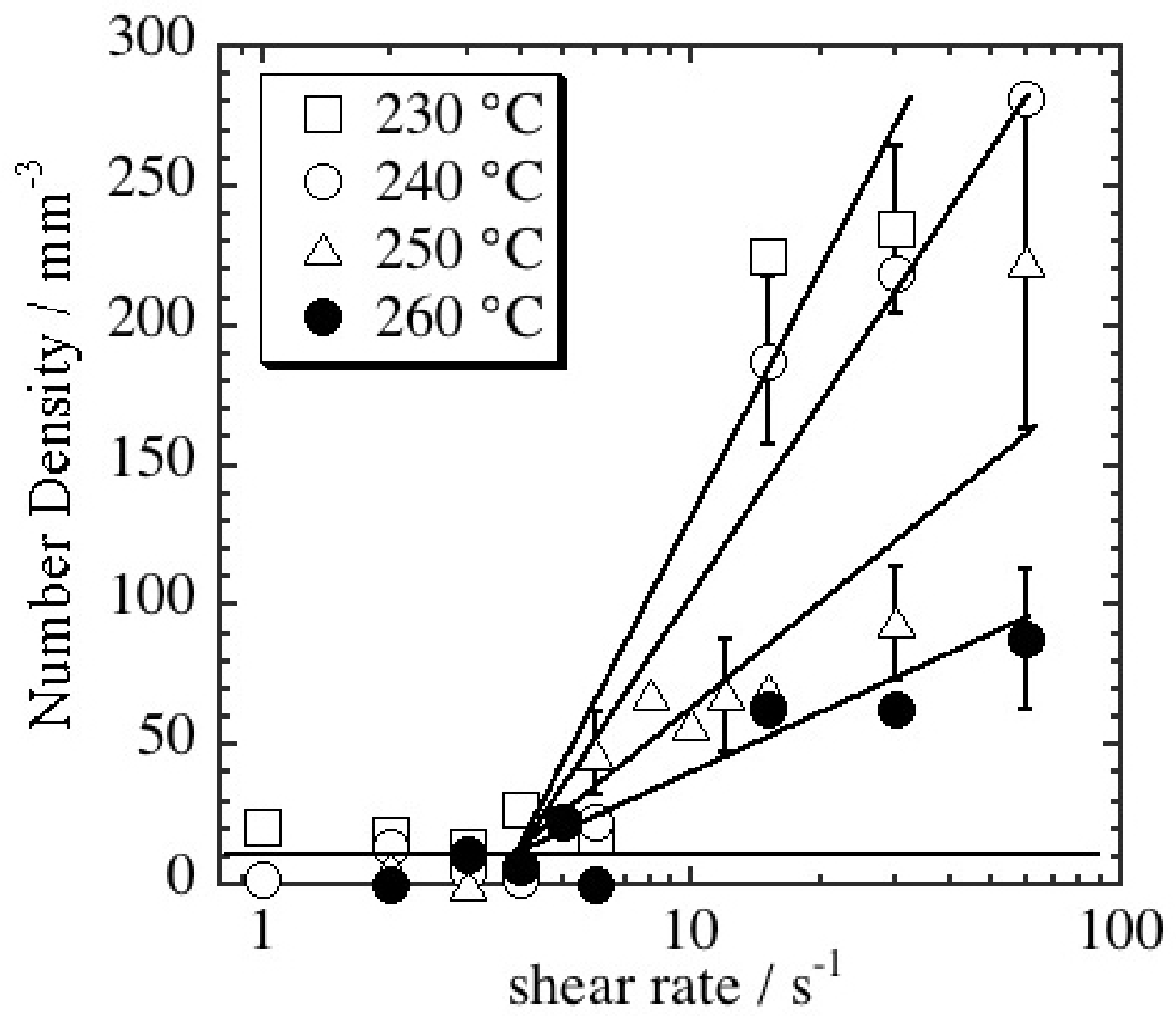

Figure 8. Number density of the string-like objects as a function of shear rate at various annealing temperatures above the nominal melting temperature $T_{\mathrm{m}}\left(=223^{\circ} \mathrm{C}\right)$. The shear stain was $12,000 \%$ for all the shear rates. 


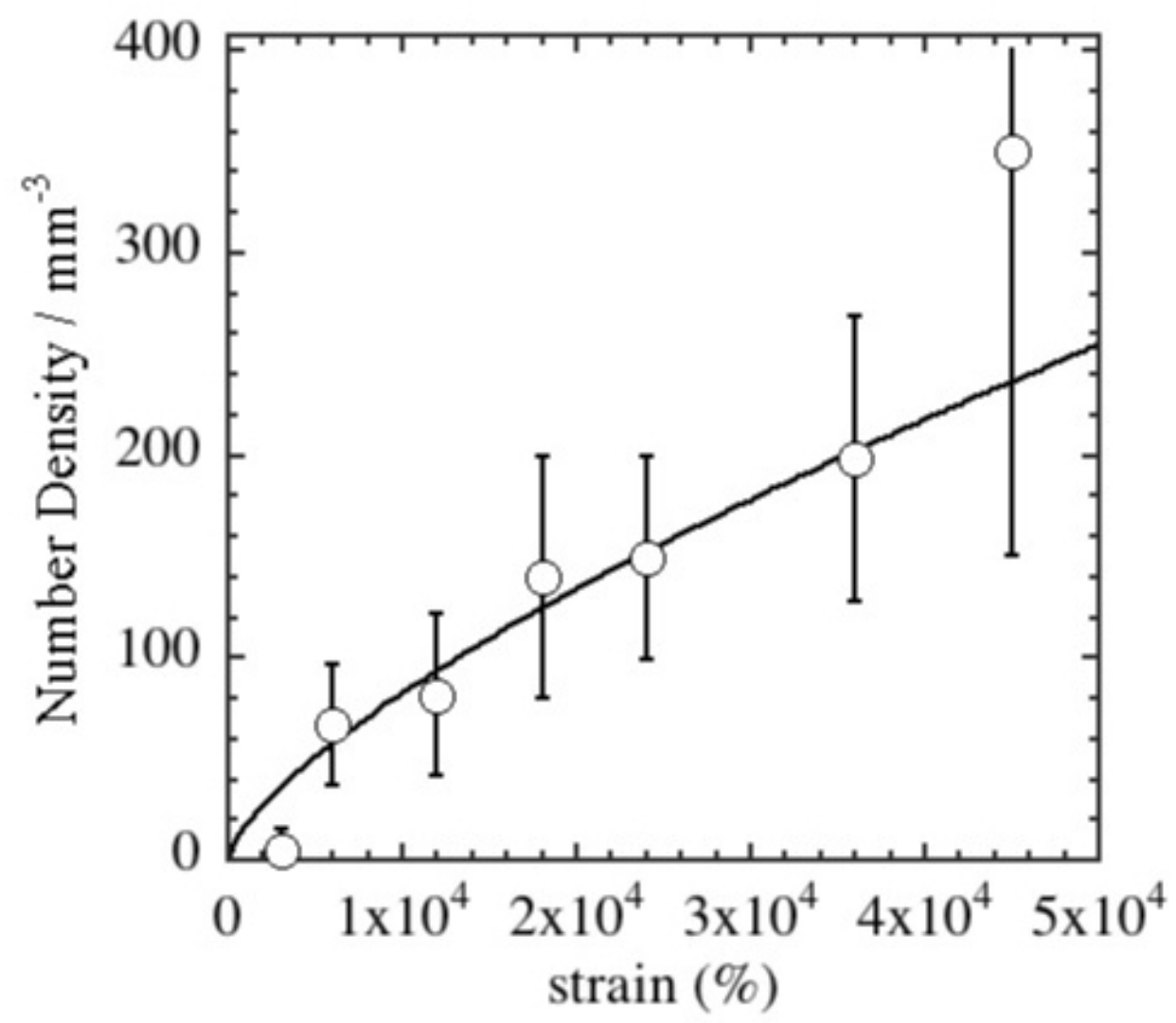

Figure 9. Number density of the string-like objects as a function of shear strain at $250{ }^{\circ} \mathrm{C}$. The shear rate was $30 \mathrm{~s}^{-1}$ for all the measurements. 

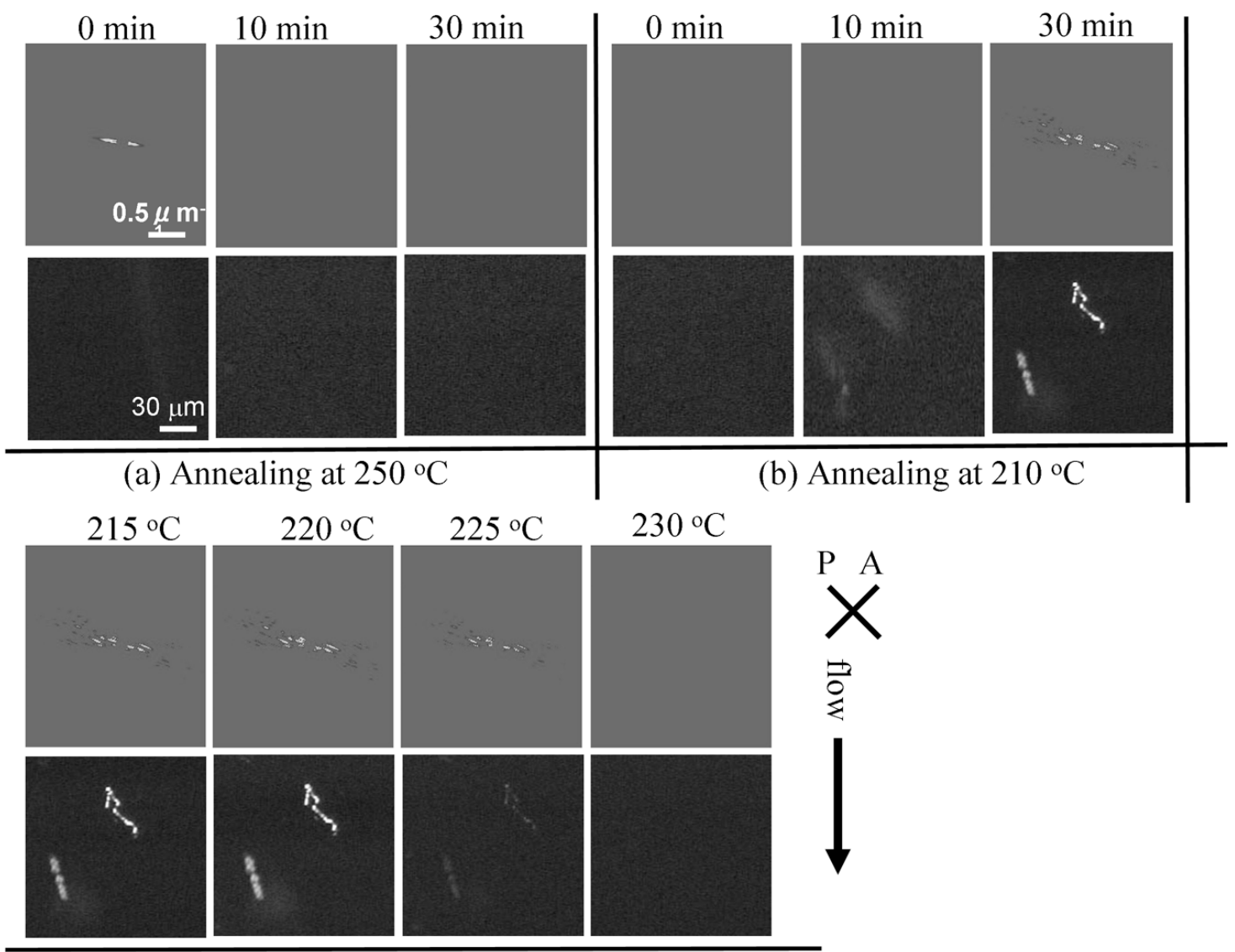

(c) Heating

Figure 10. DPLS and POM pictures after applying a pulse shear with shear rate of $1 \mathrm{~s}^{-1}$ and shear strain of $12,000 \%$ at $250{ }^{\circ} \mathrm{C}$. (a): the annealing process at $250{ }^{\circ} \mathrm{C}$, (b) the annealing process at $210^{\circ} \mathrm{C}$ after cooling, (c): the heating process from 210 to $290{ }^{\circ} \mathrm{C}$. 

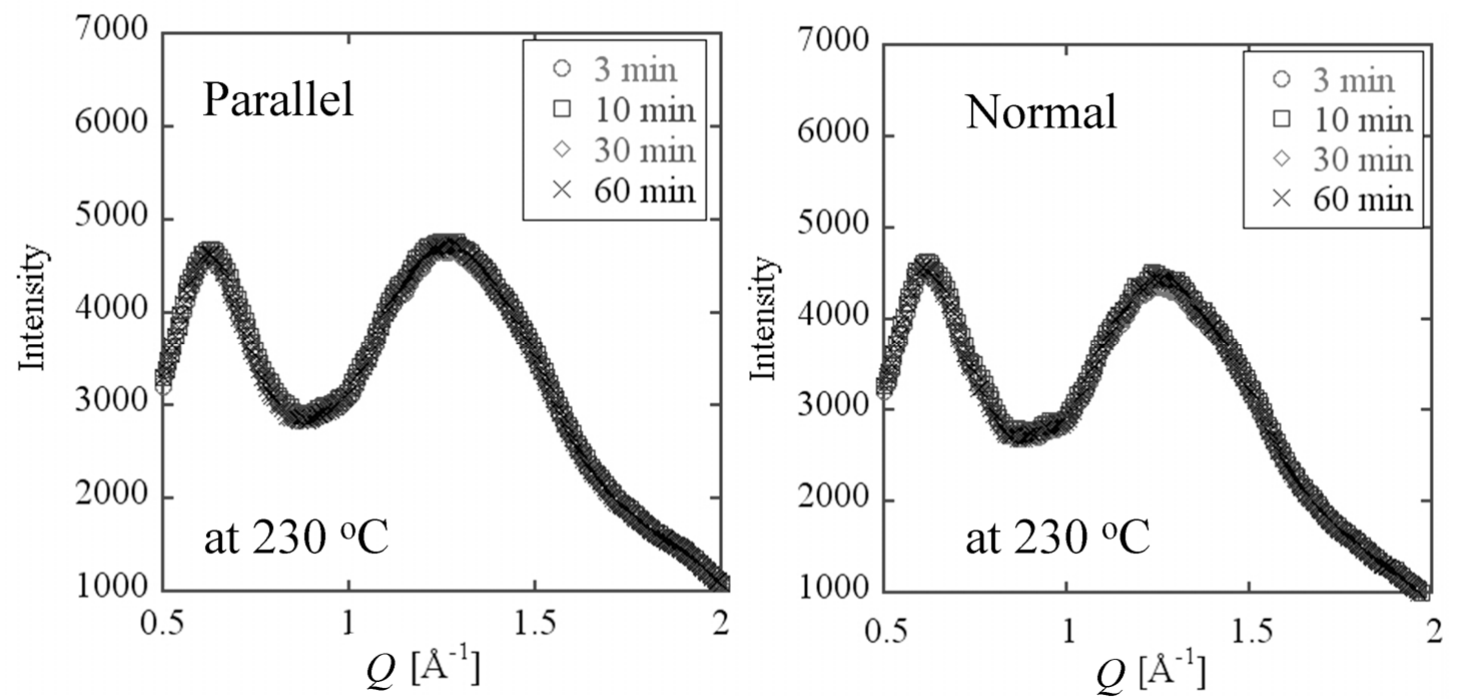

Figure 11. 1D WAXS profiles in the directions parallel and normal to the flow direction after applying a pulse shear with shear rate of $30 \mathrm{~s}^{-1}$ and strain of $12,000 \%$ at $250{ }^{\circ} \mathrm{C}$. 